\title{
DINÂMICA DA DORMÊNCIA DE GEMAS DE DOIS ANOS DE MACIEIRA 'IMPERIAL GALA' EM REGIÃO DE BAIXA OCORRÊNCIA DE FRIO ${ }^{1}$
}

\author{
RUY INACIO NEIVA DE CARVALHO² \& FLÁVIO ZANETTE ${ }^{3}$
}

\begin{abstract}
RESUMO - O objetivo deste trabalho foi determinar a dinâmica da dormência de gemas em ramos de dois anos de macieira 'Imperial Gala' com ou sem frio suplementar durante o outono e inverno, cultivadas em Porto Amazonas - PR, região de baixa ocorrência de frio. Os ramos foram coletados em intervalos de 21 dias, de abril a agosto (19-04, 10-05, 31-05, 21-06, 12-07, 02-08 e 23-08) e receberam ou não tratamento com frio suplementar de 1.440 horas, à temperatura de $4 \mathrm{a} 7^{\circ} \mathrm{C}$. A avaliação da dormência foi realizada pelo teste biológico de estacas de nós isolados (temperatura de $25^{\circ}$ C e fotoperíodo de 16 horas) por meio dos parâmetros: tempo médio para brotação (TMB), velocidade de brotação (VB), taxa final de brotação (TF), taxa de brotações vigorosas (TBV) e tempo médio para aparecimento de folhas abertas (TMFA). A dormência mais intensa de gemas de dois anos ocorre no final de maio, com oscilações até o início de agosto. A aplicação de 1.440 horas de frio suplementar de 4 a $7^{\circ} \mathrm{C}$ altera a dinâmica da dormência das gemas de dois anos, reduzindo o seu tempo médio de brotação. Uma vez propiciada a brotação de gemas não-dormentes de dois anos, as mesmas possuem boa capacidade para se desenvolver.
\end{abstract}

Termos para Indexação: Malus domestica Borkh., brotação, ecofisiologia, endodormência.

\section{DORMANCY DYNAMICS OF TWO YEAR OLD BUDS OF 'IMPERIAL GALA' APPLE TREE IN A REGION OF LOW CHILL OCCURENCE}

\begin{abstract}
This work aims to evaluate the dormancy dynamics of two year old apple tree buds with or without supplementary chill during autumn and winter, in a region of low chill occurence. The stems were collected in Porto Amazonas, Parana State, Brazil, at intervals of 21 days from April to August (April $19^{\text {th }}$, May $10^{\text {th }}$, May $31^{\text {st }}$, June $21^{\text {st }}$, July $12^{\text {th }}$, August $2^{\text {nd }}$ and August $23^{\text {rd }}$ ) and were either treated or not with 1,440 hours of chill $\left(4\right.$ to $\left.7^{\circ} \mathrm{C}\right)$. The evaluation of dormancy was observed through the biological test of single node cuttings under controlled conditions $\left(25^{\circ} \mathrm{C}\right.$ and long days of 16 hours) by the following parameters: average time for budburst (TMB), velocity of budburst (VB), final rate of budburst (TF), rate of vigorous budburst (TBV) and average time for open leaves to appear (TMFA). The most intense dormancy occured on May $31^{\text {st }}$, but presented variations until August. The chilly treatment with 1,440 hours ( 4 to $7^{\circ} \mathrm{C}$ ) was effective in reducing the average time for budburst. Non-dormant buds under favorable developing conditions present good growth potencial.
\end{abstract}

Index Terms: Malus domestica Borkh., budburst, ecophysiology, endodormancy.

\section{INTRODUÇÃO}

As baixas temperaturas de outono e inverno constituem o fator ambiental de maior influência na dinâmica da dormência de gemas da macieira (Petri et al., 1996), em especial durante a endodormência em que a paralisação do desenvolvimento da gema é resultante de uma série de eventos bioquímicos e fisiológicos que acontecem em tecidos meristemáticos ou regiões muito próximas (Lang et al., 1987).

As variações de temperatura influenciam nos processos fisiológicos internos envolvidos na entrada e saída da endodormência que podem estar relacionados com fatores diversos ligados à anatomia, fisiologia ou metabolismo da planta (Bonhomme et al., 2000; Stafstrom, 2000; Tamura et al., 1998).

As respostas das gemas em relação à exposição às baixas temperaturas são variadas de acordo com as cultivares analisadas, tipo de gema (vegetativa ou florífera) e sua localização na planta (Petri et al., 1996; Putti et al., 2003a; Putti et al., 2003b). Gemas de idades distintas também podem apresentar respostas variadas em relação ao frio, pois gemas dormentes de dois e três anos em macieiras adultas podem apresentar brotação espontânea quando ocorrem temperaturas elevadas no inverno, enquanto gemas de um ano permanecem dormentes. Estas gemas poderiam ser importantes na correção da copa da planta ou para renovação de ramos produtivos, porém, ao final da endodormência e início da ecodormência, período em que a brotação não ocorre por fatores externos à planta (Lang et al., 1987), a capacidade de brotação de gemas de um ano já se torna maior que a das gemas mais velhas. Assim, as gemas mais novas brotam, assumem o novo ciclo de crescimento e inibem a brotação das gemas mais velhas, caracterizando a acrotonia em plantas lenhosas (Meng Horn et al., 1975), fato indesejável em pomares comerciais de macieira.

Os métodos desenvolvidos para a avaliação da dormência de gemas são utilizados para avaliar a capacidade de brotação de gemas de um ano de idade. Porém, o conhecimento do potencial de brotação de gemas mais velhas de macieira e sua relação com a intensidade de frio no outono e inverno pode esclarecer a fisiologia da dormência das mesmas e fornecer subsídios para uso de técnicas que favoreçam a sua brotação para melhor crescimento da planta.

O objetivo deste trabalho foi determinar a dinâmica da dormência de gemas em ramos de dois anos de macieira 'Imperial Gala', com ou sem frio suplementar, durante o outono e inverno, cultivadas em Porto Amazonas - PR, região de baixa ocorrência de frio.

\section{MATERIALEMÉTODOS}

O trabalho foi realizado em ramos com gemas dormentes de dois anos de macieira 'Imperial Gala' (porta-enxerto M-26) coletados no período de abril a agosto de 2000, em pomar com 5 anos de idade, conduzido em plantio adensado $(4,0$ x 1,35 m) na Fazenda Agropecuária

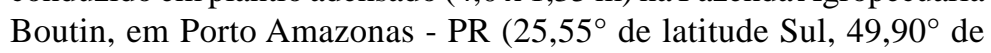
longitude Oeste e $795 \mathrm{~m}$ de altitude).

A quantificação do frio ocorrido na região durante o outono e inverno do ano anterior (1999) e do ano estudado (2000) foi determinada segundo o método do número de horas de frio (HF) abaixo de $7,2^{\circ} \mathrm{Ce}$ pelo método da conversão de temperaturas para unidades de frio (UF), conforme Carvalho (2001) (Tabelas 1 e 2). A quantidade de frio ocorrido no período estudado foi acima da média da região desde a instalação do pomar em 1995.

\footnotetext{
${ }^{1}$ (Trabalho 072/2004). Recebido: 16/06/2004. Aceito para publicação: 28/10/2004. Parte da tese do primeiro autor apresentada à Universidade Federal do Paraná para obtenção do título de Doutor em Ciências.

${ }^{2}$ Engenheiro Agrônomo, Dr., Professor Titular do Centro de Ciências Agrárias e Ambientais da Pontifícia Universidade Católica do Paraná. Rodovia BR 376 , Km 14, CEP 83010-500 - São José dos Pinhais - PR. Fone: (41) 382-1454. ruy.carvalho@ pucpr.br.

${ }^{3}$ Eng. Agrônomo, Dr., Professor de Fruticultura do Departamento de Fitotecnia e Fitossanitarismo da Universidade Federal do Paraná. Rua dos Funcionários, 1540, CEP 80035-050. Curitiba-Paraná. Fone: (41) 350-5650. flazan@ufpr.br.
} 
TABELA 1 - Quantificação de frio ocorrido no período de maio a agosto, segundo os modelos de horas de frio (HF) e unidades de frio (UF), baseada nos dados de temperatura horária fornecidos pelo SIMEPAR. Porto Amazonas - Paraná, 1999.

\begin{tabular}{lcccc}
\hline Mês/1999 & \multicolumn{2}{c}{ Horas de frio } & $7,2^{\circ} \mathrm{C}$ & \multicolumn{2}{c}{ Unidades de frio } \\
\cline { 2 - 5 } & No mês & Acumulado & No mês & Acumulado \\
\hline Maio & 83 & 83 & 78,0 & 78,0 \\
Junho & 64 & 147 & 209,5 & 287,5 \\
Julho & 31 & 178 & 129,0 & 416,5 \\
Agosto & 98 & 276 & $-54,5$ & 362,0 \\
\hline
\end{tabular}

TABELA 2 - Quantificação de frio ocorrido no período de maio a agosto, segundo os modelos de horas de frio (HF) e unidades de frio (UF), baseada nos dados de temperatura horária, com ênfase nas datas de coleta dos ramos para avaliação. Porto Amazonas - Paraná, 2000.

\begin{tabular}{lcccc}
\hline Período/2000 & \multicolumn{2}{c}{ Horas de frio } & $7,2^{\circ} \mathrm{C}$ & \multicolumn{2}{c}{ Unidades de frio } \\
\cline { 2 - 5 } & No período & Acumulado & No período & Acumulado \\
\hline $1^{\circ}$ a $10-05$ & 18 & 18 & $-63,5$ & $-63,5$ \\
10 a $31-05$ & 39 & 57 & 98,0 & 34,5 \\
$31-05$ a 21-06 & 7 & 64 & $-74,5$ & $-40,0$ \\
$21-06$ a 12-07 & 31 & 95 & $-46,0$ & $-86,0$ \\
$12-07$ a $02-08$ & 232 & 327 & 242,0 & 156,0 \\
$02-08$ a 23-08 & 59 & 386 & 55,5 & 211,5 \\
\hline
\end{tabular}

Os ramos com inserção e disposição espacial oblíqua foram coletados em sete épocas distintas: 19-04, 10-05, 31-05, 21-06, 12-07, 02-08 e 23-08. Após cada coleta, os ramos receberam ou não tratamento com frio suplementar de 1.440 horas realizado em geladeira, à temperatura de $4 \mathrm{a} 7^{\circ}$ $\mathrm{C}$ no escuro, com os ramos acondicionados na posição vertical, com a porção basal dentro de um vaso com vermiculita umedecida para a manutenção da umidade.

A avaliação da dormência foi realizada por meio do teste biológico de estacas de nós isolados, realizado em sala de crescimento, à temperatura de $25^{\circ} \mathrm{C}$ e fotoperíodo de 16 horas, no Laboratório de Micropropagação de Plantas do Departamento de Fitotecnia e Fitossanitarismo da Universidade Federal do Paraná. A porção mediana dos ramos foi dividida em estacas de $7 \mathrm{~cm}$ de comprimento, mantendo-se nas mesmas apenas a gema superior. Os testes foram realizados com quatro repetições de 10 estacas acondicionadas em vasos com vermiculita como substrato, totalizando 40 estacas por tratamento. Cada vaso representou uma unidade experimental.

As estacas foram avaliadas individualmente a cada dois dias, até um período máximo de 40 dias, de acordo com os parâmetros de crescimento "Ponta Verde" (PV) (aparecimento de modificações na coloração da gema, ficando esta com o ápice esverdeado) e "Gema Aberta" (GAb) (aparecimento de folhas abertas). Com base nestes parâmetros, foram calculadas as seguintes variáveis conforme utilizado Carvalho (2001):

- Tempo médio para brotação (TMB): número médio de dias passados entre a instalação do experimento, em cada data, e a detecção do estádio PV.

- Velocidade de brotação (VB): ocorrência de brotação das gemas, em função do tempo, para brotação dada pela equação:

em que:

$$
\mathrm{VB}=\sum\left(\mathrm{n}_{\mathrm{i}} / \mathrm{t}_{\mathrm{i}}\right)(\text { gemas/dia })
$$

$\mathrm{n}_{\mathrm{i}}=$ número de gemas que atingiram o estádio PV no tempo "i";

$\mathrm{t}_{\mathrm{i}}=$ tempo após instalação do teste $(\mathrm{i}=1 \rightarrow 40)$.

- Taxa final de brotação (TF): porcentagem de estacas com gemas que atingiram o estádio PV.

- Taxa de brotações vigorosas (TBV): porcentagem das estacas com gemas no estádio PV que evoluíram até o estádio GAb no período analisado.

(\% de estacas com gemas no estádio GAb) x 100
- Tempo médio para aparecimento de folhas abertas (TMFA): número médio de dias passados entre o estádio PV e GAb.

$\mathrm{O}$ delineamento experimental adotado foi o de parcelas subdivididas no tempo, com o fator principal arranjado em blocos casualizados, com quatro repetições. A parcela principal foi o tratamento ou não com frio suplementar, e as subparcelas foram as sete datas de coleta, totalizando 14 tratamentos. A comparação entre médias de tratamentos foi feita pelo teste Tukey, a $5 \%$ de probabilidade.

\section{RESULTADOS E DISCUSSÃO}

A dormência mais profunda de gemas de dois anos não tratadas com frio suplementar ocorreu no final de maio (Figura 1), representada pelo pico da curva do tempo médio para brotação (TMB), porém houve uma oscilação da intensidade da dormência até o início de agosto. Em gemas de um ano coletadas nas mesmas plantas e no mesmo período, a dormência foi mais intensa e mais definida no mês de julho, sem oscilações posteriores (Carvalho, 2001). A rápida evolução da dormência no período de abril a maio, mesmo com baixa ocorrência de frio (34,5 unidades de frio, conforme Tabela 2), salienta a possível interferência de outro fator ambiental da época representado pela redução do fotoperíodo.

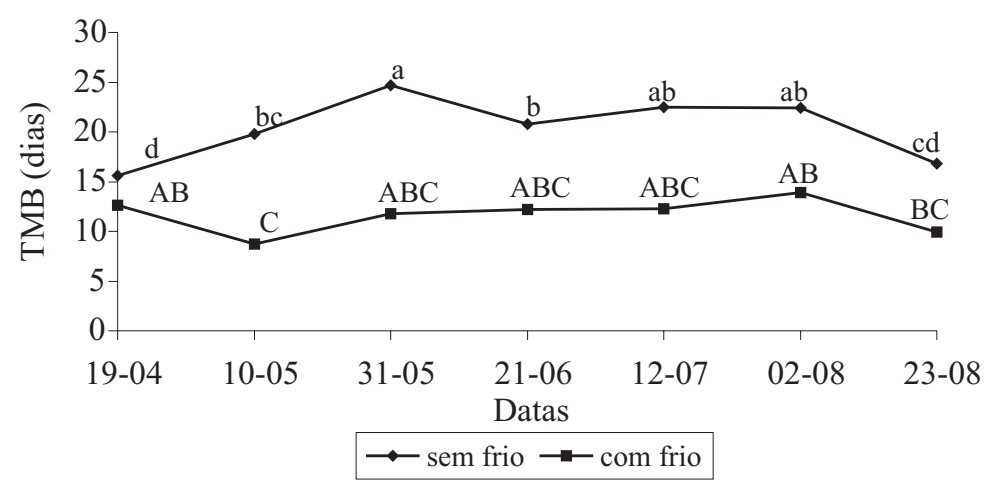

FIGURA 1 - Dinâmica do tempo médio para brotação (TMB) de gemas de dois anos de idade de macieira 'Imperial Gala' que receberam ou não 1.440 horas de frio suplementar de $4 \mathrm{a} 7^{\circ} \mathrm{C}$. Médias seguidas por letras distintas diferem entre si, pelo Teste de Tukey, a $5 \%$ de probabilidade. Porto Amazonas - Paraná, 2000. $(\mathrm{cv}=5,0 \%)$.

A queda do TMB a partir do pico da curva caracteriza o final da endodormência, demonstrando maior aptidão da gema à brotação. Assim, as oscilações ocorridas para as gemas de dois anos podem significar que a dormência não foi homogeneamente superada no inverno, possivelmente pela baixa ocorrência de frio na região.

A dormência menos intensa ocorrida em 21-06 não resulta em brotação de gemas na planta, pois, apesar do frio pouco intenso, as condições ambientais não são favoráveis ao crescimento das gemas neste período. Assim, pode ocorrer novo aumento da intensidade de dormência nestas gemas que são induzidas a permanecerem dormentes, pois, na época mais propícia à brotação, final do inverno, brotam as gemas terminais de ramos de um ano, menos dormentes (Faust et al., 1995). Quando as gemas de dois anos estão naturalmente aptas a brotar, caracteriza-se a basitonia no ramo, porém, em condições naturais, a basitonia raramente se expressa em plantas lenhosas durante o outono e o inverno (Meng Horn et al., 1975).

O tratamento com 1.440 horas de frio suplementar reduziu significativamente a intensidade de dormência das gemas de dois anos em todos os meses estudados (Figura 1), indicando que estas gemas também respondem ao tratamento com frio, assim como as gemas de um ano (Carvalho, 2001). Esta resposta confirma a forte influência do tratamento com frio na evolução da dormência, conforme afirmaram Flore \& Layne (1996) e Pereira et al. (2001).

Apesar de a ocorrência de frio no ano de 1999 ter sido superior à do ano de 2000, ainda foi abaixo dos níveis mínimos requeridos pela macieira 'Gala', a qual originou a 'Imperial Gala', que exige até 600 horas de 
frio para a superação da dormência (Petri et al., 1996). Em 1999, ocorreram 276 horas de frio ou 362 unidades de frio (Tabela 1), fato que determinou a dormência das gemas neste ano. Muitas daquelas gemas que não brotaram na primavera de 1999, voltaram a não brotar em 2000, conforme se verificou pela baixa taxa final de brotação (Tabela 3). Este fato indica que, uma vez dormente, uma gema está destinada a permanecer dormente e somente apresentar brotação extemporânea quando algum fator externo permitir sua brotação, como a poda de ramos velhos. Pode-se considerar que estas gemas permanecem como gemas de reserva, uma vez que, mesmo não brotadas em um ano, possuem capacidade de brotação no ano seguinte quando isoladas ou retiradas de uma posição inferior em relação a outras gemas.

O tratamento com frio suplementar aumentou significativamente a velocidade de brotação e a taxa final de brotação das gemas tratadas em relação às não-tratadas, principalmente no período de evolução da dormência (Tabela 3). $\mathrm{O}$ frio suplementar também eliminou as diferenças da taxa final de brotação entre as datas de coleta, atingindo valores de até $100 \%$. Da mesma forma, o frio proporcionou uma taxa de brotações vigorosas próxima de $100 \%$, indicando que uma vez induzida a brotação de gemas de dois anos não dormentes, as mesmas possuem capacidade para se desenvolver, sem apresentar algum impedimento para o suprimento da água e reservas necessárias à expansão foliar (Tabela 4).

O efeito do frio não foi significativo apenas para o tempo médio para aparecimento de folhas abertas, indicando que, em qualquer fase do período de dormência, as gemas vigorosas aptas a iniciar e continuar o crescimento comportaram-se de forma semelhante (Tabela 4).

TABELA 3 - Velocidade de brotação (VB) e taxa final de brotação (TF) resultantes do teste biológico com estacas de macieira 'Imperial Gala', com 2 anos de idade, que receberam ou não 1.440 horas de frio suplementar, no período de abril a agosto de 2000. Porto Amazonas - Paraná, 2000.

\begin{tabular}{|c|c|c|c|c|c|c|c|c|}
\hline \multirow[t]{2}{*}{ Datas } & \multicolumn{4}{|c|}{ VB (gemas/dia) } & \multicolumn{4}{|c|}{$\mathrm{TF}(\%)$} \\
\hline & \multicolumn{2}{|c|}{ Sem frio } & \multicolumn{2}{|c|}{ Com frio } & \multicolumn{2}{|c|}{ Sem frio } & \multicolumn{2}{|c|}{ Com frio } \\
\hline $19-04$ & $0,57 \mathrm{~A}^{*}$ & $\mathrm{~b}$ & $0,76 \mathrm{C}$ & $\mathrm{a}$ & $85,0 \mathrm{~A}$ & $\mathrm{a}$ & $85,0 \mathrm{~A}$ & $\mathrm{a}$ \\
\hline $10-05$ & $0,23 \mathrm{BC}$ & b & $1,20 \mathrm{~A}$ & $\mathrm{a}$ & $42,5 \mathrm{BC}$ & b & $97,5 \mathrm{~A}$ & $\mathrm{a}$ \\
\hline $31-05$ & $0,17 \mathrm{BC}$ & b & $0,90 \mathrm{BC}$ & $\mathrm{a}$ & $40,0 \mathrm{BC}$ & b & $100 \mathrm{~A}$ & $\mathrm{a}$ \\
\hline $21-06$ & $0,22 \mathrm{BC}$ & b & $0,91 \mathrm{BC}$ & $\mathrm{a}$ & $45,0 \mathrm{BC}$ & b & $97,5 \mathrm{~A}$ & $\mathrm{a}$ \\
\hline $12-07$ & $0,11 \mathrm{C}$ & b & $0,81 \mathrm{C}$ & $\mathrm{a}$ & $25,0 \mathrm{CD}$ & b & $95,0 \mathrm{~A}$ & $\mathrm{a}$ \\
\hline 02-08 & $0,08 \mathrm{C}$ & b & $0,55 \mathrm{D}$ & $\mathrm{a}$ & $17,5 \mathrm{D}$ & $\mathrm{b}$ & $75,0 \mathrm{~A}$ & $\mathrm{a}$ \\
\hline $23-08$ & $0,37 \mathrm{~B}$ & b & $1,01 \mathrm{AB}$ & $\mathrm{a}$ & $57,5 \mathrm{AB}$ & b & $92,5 \mathrm{~A}$ & $\mathrm{a}$ \\
\hline
\end{tabular}

*Médias seguidas por letras maiúsculas distintas nas colunas ou por letras minúsculas distintas nas linhas dentro de cada variável diferem entre si, pelo Teste de Tukey, a $5 \%$ de probabilidade.

TABELA 4 - Tempo médio para aparecimento de gemas abertas (TMFA) e taxa de brotações vigorosas (TBV) resultantes do teste biológico com estacas de macieira 'Imperial Gala', com 2 anos de idade, que receberam ou não 1.440 horas de frio suplementar, no período de abril a agosto. Porto Amazonas - Paraná, 2000.

\begin{tabular}{lcccccc}
\hline Datas & \multicolumn{3}{c}{ TMFA (dias) } & \multicolumn{4}{c}{ TBV (\%) } \\
\cline { 2 - 7 } & Sem frio & Com frio & \multicolumn{2}{c}{ Sem frio } & \multicolumn{2}{c}{ Com frio } \\
\hline $19-04$ & $3,1^{\mathrm{ns}}$ & $2,6^{\text {ns }}$ & $97,2 \mathrm{~A}^{*}$ & a & $96,9 \mathrm{~A}$ & $\mathrm{a}$ \\
$10-05$ & 2,4 & 4,2 & $62,5 \mathrm{~B}$ & $\mathrm{~b}$ & $100 \mathrm{~A}$ & $\mathrm{a}$ \\
$31-05$ & 2,4 & 3,6 & $91,7 \mathrm{~A}$ & $\mathrm{a}$ & $100 \mathrm{~A}$ & $\mathrm{a}$ \\
$21-06$ & 2,9 & 3,5 & $100 \mathrm{~A}$ & $\mathrm{a}$ & $100 \mathrm{~A}$ & $\mathrm{a}$ \\
$12-07$ & 3,8 & 3,1 & $83,4 \mathrm{~A}$ & $\mathrm{~b}$ & $100 \mathrm{~A}$ & $\mathrm{a}$ \\
$02-08$ & 3,1 & 3,5 & $100 \mathrm{~A}$ & $\mathrm{a}$ & $100 \mathrm{~A}$ & $\mathrm{a}$ \\
$23-08$ & 3,0 & 2,9 & $100 \mathrm{~A}$ & a & $97,5 \mathrm{~A}$ & $\mathrm{a}$ \\
\hline cv $(\%)$ & Datas: 19,3 & Frio: 33,1 & Datas: 1,6 & \multicolumn{2}{c}{ Frio: 4,5} \\
\hline
\end{tabular}

*Médias seguidas por letras maiúsculas distintas nas colunas ou por letras minúsculas distintas nas linhas dentro de cada variável diferem entre si, pelo Teste de Tukey, a $5 \%$ de probabilidade.

${ }^{\text {ns} M e ́ d i a s ~ s e m ~ d i f e r e n c ̧ a ~ s i g n i f i c a t i v a . ~}$

\section{CONCLUSÕES}

A dormência mais intensa de gemas de dois anos de macieira 'Imperial Gala', cultivada em região de baixa ocorrência de frio (Porto Amazonas, Paraná), ocorre no final de maio, com oscilações até o início de agosto.

A aplicação de 1.440 horas de frio suplementar de 4 a $7^{\circ} \mathrm{C}$ altera a dinâmica da dormência das gemas de dois anos, reduzindo o seu tempo médio de brotação.

Uma vez induzida a brotação de gemas de dois anos não dormentes, as mesmas possuem capacidade para se desenvolver.

\section{REFERÊNCIAS}

BONHOMME, M.; RAGEAU, R.; GENDRAUD, M. ATP, ADP and NTP contents in vegetative and floral peach buds during winter: are they useful for characterizing the type of dormancy? In: VIÉMONT, J.D.; CRABBÉ, J. (Ed.) Dormancy in plants: from whole plant behaviour to cellular control. Cambridge: University Press, 2000. p.245-257.

CARVALHO, R. I. N. Dinâmica da dormência e do conteúdo de carboidratos e proteínas em gemas vegetativas e ramos de um e dois anos de macieira com ou sem frio suplementar. 2001. 134f. Tese (Doutorado em Produção Vegetal), Setor de Ciências Agrárias, Universidade Federal do Paraná, Curitiba, 2001.

FAUST, M.; LIU, D.; WANG, S. Y.; STUTTE, G. W.; POWELL, L. E.; IWAHORI, S.; COUVILLON, G. A. Involvement of apical dominance in winter dormancy of apple buds. Acta Horticulturae, Wageningen, n.395, p.47-56, 1995.

FLORE, J. A.; LAYNE, D. R. Prunus. In: ZAMSKI, E.; SCHAFFER, A. A. Photoassimilate distribution in plants and crops: source-sink relationships. New York: Marcel Dekker, 1996. p.825-849.

LANG, G. A.; EARLY, J. D.; MARTIN, G. C.; DARNELL, R. L. Endo-, paraand ecodormancy: physiological terminology and classification for dormancy research. Hortscience, Alexandria, v.22, p.371-178, 1987.

MENG HORN, C.; CHAMPAGNAT, P.; BARNOLA, P.; LAVARENNE, S. L'axe caulinaire, facteur de préséance entre bourgeon sur le rameau de l'année du Rhamnus frangula L. Physiologie Végétale, Paris, v.13, n.3, p.335-348, 1975.

PEREIRA, J. E. S.; FORTES, G. R. L.; SILVA, J. B. Efeito da aplicação de baixa temperatura em plantas de macieira sobre o crescimento durante a aclimatização. Pesquisa Agropecuária Brasileira, Brasília, v.36, n.1,p.89-95, 2001

PETRI, J. L.; PALLADINI, L. A.; SCHUCK, E.; DUCROQUET, J. P.; MATOS, C. S.; POLA, A. C. Dormência e indução da brotação de fruteiras de clima temperado. Florianópolis: EPAGRI, 1996. 110p. (Boletim Técnico, 75).

PUTTI, G. L.; PETRI, J. L.; MENDEZ, M. E. Efeito da intensidade do frio no tempo e percentagem de gemas brotadas em macieira. Revista Brasileira de Fruticultura, Jaboticabal, v.25, n.2, p.199-202, $2003 \mathrm{a}$.

PUTTI, G. L.; PETRI, J. L.; MENDEZ, M. E. Temperaturas efetivas para a dormência da macieira (Malus domestica Borkh.). Revista Brasileira de Fruticultura, Jaboticabal, v.25, n.2, p.210-212, 2003b.

STAFSTROM, J. P. Regulation of growth and dormancy in pea axillary buds. In: VIÉMONT, J.-D.; CRABBÉ, J. (Ed.). Dormancy in plants: from whole plant behaviour to cellular control. Cambridge: University Press, 2000. p.331-346.

TAMURA, F.; TANABE, K.; ITAI, A.; TANAKA, H. Protein changes in the flower buds of japanese pear during breaking of dormancy by chiling or high-temperature treatment. Journal of the American Society for Horticultural Science, Alexandria, v.123, n.4, p.532-536, 1998. 